\title{
A coalescent space for bio-cultural knowledge to flourish
}

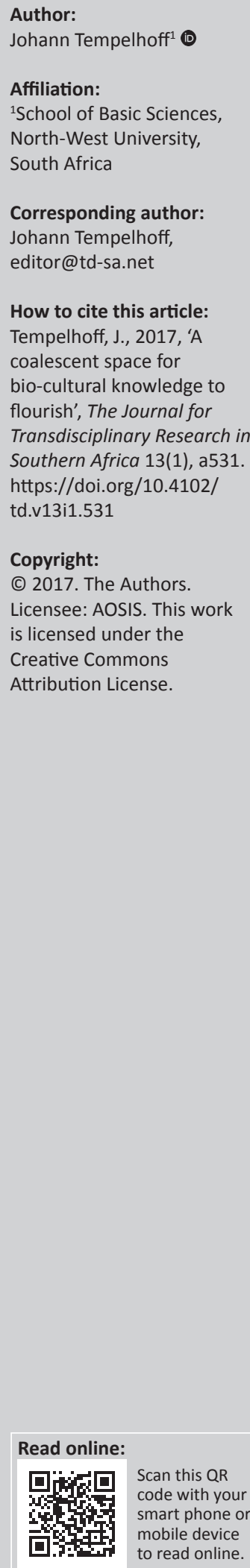

At the end of its second year as open access journal in the AOSIS stable, The Journal for Transdisciplinary Research in Southern Africa is clearly in the process of acquiring a more nuanced identity. For one, the editorial content suggests that there is a greater tendency towards diversity and explorative encounters beyond the confines of singular disciplines.

Another interesting development is more material from neighbouring southern African states. Muphoshi and Dhurup report on consumer attitudes to ethanol-blended fuel in Zimbabwe, while Chari and Ngcamu explore collaborative strategies in disaster risk reduction in the Zimbabwe dairy supply chain. Nyandoro and Muzorewa focus on the transition from growth point policy to liberal urban development in the case of the town of Ruwa in Zimbabwe. Tunamisifu discusses the Ezulwini Consensus in the early 2010s when the African Great Lakes Region was affected by violence in the eastern Democratic Republic of Congo. The study forms part of the continental work conducted at the Institute for Dispute Resolution in Africa at the University of South Africa.

For readers with an appetite for the debate between science and society, there is also food for thought. Kroeze provocatively argues that science is in serious trouble as a result of clashes between interests of people and those of influential corporate and political role players. This has cast a shadow of doubt on science and its methodologies. Society, at large, is becoming critical of science and its 'groundbreaking' findings. Kroeze's argument is informed by two apparently contested areas: climate change and new trends in dietary sciences. In the scientific realm, where induction or empiricism and deduction or rationalism are dominant foci, the conflict areas between science and politics are critical thinking in legal studies. She argues that the apparent conundrum has reached the point where law is equated with politics. The readers are therefore left to grapple with intellectual spaces where 'science is politics'.

While multidisciplinary practice maintains a strong presence in most research output, there remains a growing need for transdisciplinarity. Given the rapid rate of development in a large number of fields, transdisciplinarity is singled out in some circles as tertiary education's development route for the next decade (Murday 2013). There has been convergence in the fields of nanotechnology, biology and information communications systems. American futurists now suggest that there are indications of new emergent trends. There is a high degree of integration of some substantially greater knowledge sets in new spaces of intellectual activity. The process requires attention in an environment in which the physical infrastructure will increasingly make more complex demands on society. Data analytics and comprehensive digital data sets are bound to become more important in the fields of social sciences and humanities. Relying on statistical inferences is increasingly becoming more pervasive in the fields of cognition and emotion and our understanding of human behaviours.

In our own backyard, southern Africa, there is much promise. Although we may not yet be at the forefront of the latest developments in the politics and economics of private enterprise's artificial intelligence and robotics research breakthroughs, we are getting there - albeit it on a different development pathway. Currently the disciplines of public management and governance as well as disaster studies amongst the avant-garde social science-related disciplines have made significant inroads into transdisciplinary spaces of engagement. In this issue, there is evidence that our researchers are broadening their vistas and are becoming more literate and familiar with the challenges of the local, national and international environments.

Other contributions in this edition blend sports studies and music, while educational thinking is extended to the aesthetics of architecture and spatial planning. In history, there is a focus on international economics in the second half of the 20th century. It is material that deserves the attention of serious economists. Similar contributions of geography, politics and economics are 
represented in this issue. There are promising signs of a broadening knowledge gaze.

These initiatives deserve support. On the African continent - potentially one of the last underdeveloped regions of the world - there is a distinct need for the production of knowledge that explores fields of importance for development and the continent's growth. There is good reason for practitioners of transdisciplinarity to take pride in their successes in working towards resolving complex problems. Africa still has many issues that need to be addressed.
For one, we have to explore international and exogenous knowledge with a view to working towards its greater integration with our indigenous African knowledge systems. It is necessary to create a coalescent space for integrated biocultural knowledge to coexist and flourish. Transdisciplinary research can make a valuable contribution in this respect.

\section{Reference}

Murday, J., Bell, L., Heath, J., Kong, C., Chang, R., Fonash, S. et al., 2013, 'Implications: People and physical infrastructure', in M.C. Roco et al. (eds.), Convergence of
knowledge, technology and society: Beyond convergence of nano-bio-infocognitive technologies, pp. 295-297, Springer, Cham 